\title{
Technique of cavoatrial tumor thrombectomy without cardiopulmonary by-pass
}

\author{
Bhushan Patil ${ }^{1}$, Nikhar Jain ${ }^{1}$, S. K. Patwardhan ${ }^{1}$, Amit Bellurkar ${ }^{1}$ \\ ${ }^{1}$ Department of Urology, KEM Hospital, Mumbai, India
}

\begin{abstract}
Introduction: Open surgery for tumor thrombi in atria is very challenging and are associated with significant morbidity and mortality rates. Here, we explore safety of foleys catheter assisted-technique, obviating the need for open surgery. Material and Methods: We performed Radical nephrectomy via the midlineincision for renal cell carcinoma with tumor thrombus extending into the right atrium. CTVS team was kept in standby all the time. Intra-operative ECHO was used for monitoring any migration of thrombi into pulmonary. Vessels.

Results: Mean duration of surgery was roughly 4 hours. The time of total IVC occlusion was 2 minutes. The total blood loss was $2350 \mathrm{ml}$. Intraoperative ECHO showed complete removal of tumor thrombi.

Conclusions: This procedure can be performed in high risk patients with solitary large tumor thrombi.
\end{abstract}

\section{CONFLICT OF INTEREST}

None declared.

\section{ARTICLE INFO}

\section{Nikhar Jain}

http://orcid.org/0000-0002-1435-8498

Available at: http://www.intbrazjurol.com.br/video-section/20190076_Patil_et_al Int Braz J Urol. 2020; 46 (Video \#16): 677-677

Submitted for publication:

February 06, 2019

Accepted after revision:

May 31, 2019

Published as Ahead of Print:

August 10, 2019
Correspondence address: Nikhar Jain, MD Department of Urology, KEM Hospital, Mumbai, India B207 Shiv Shakti Apartment. Eknath Ghadi Marg, G E Ambekar Marg. Lower Parel Maharashtra Dadar, Mumbai 400012, India E-mail: nikhar.aryan@gmail.com 